\title{
Making Every Police-Citizen Interaction Count
}

\section{The Challenges of Building a Better Cop}

\author{
Lorraine Mazerolle \\ The University of Queensland
}

William Terrill

Arizona State University

$\mathrm{P}$ rocedural justice policing is considered to be central to better policing (President's Task Force on 21st Century Policing, 2015). To implement procedural justice policing, police need to understand and build four key principles into their interactions with members of the public: (1) treating people with respect, (2) being neutral in their decision making, (3) conveying trustworthy motives, and (4) giving citizens a voice during the encounter. Drawing on these principles in a genuine manner underpins the quality of the dialogic interaction (Bottoms and Tankebe, 2012). It is not just enough to say polite things; the manner in which polite phrases and directives are communicated in both short and long encounters makes the difference between people believing the procedures used by police to reach an outcome are fair or not (Tyler, 2006 [1990]; Tyler, Fagan, and Geller, 2014).

Emily Owens, David Weisburd, Karen Amendola, and Geoffrey Alpert (2017, this issue) use a randomized field trial in Seattle to explore whether training and supervision can "build a better cop." In this case, better cops are those who consciously slow down their thought processes to use the principles of procedural justice during different types of everyday (short and long) citizen encounters. This trial is one in a series of randomized controlled field trials (RCTs) in policing that has evaluated whether police can be trained to use procedural justice in their everyday encounters (e.g., Bates, Antrobus, Bennett, and Martin, 2015; Lowrey, Maguire, and Bennett, 2016; MacQueen and Bradford, 2015; Mazerolle, Bennett, Antrobus, and Eggins, 2012; Sahin, Braga, Apel, and Brunson, 2016; 
Thompson, 2016; Wheller, Quinton, Fildes, and Mills, 2013). Specifically, Owens et al. found that officers who were randomly assigned to participate in procedural justice training and supervisory oversight were as engaged in the community as similarly situated officers, but they were less likely to resolve incidents with an arrest or to be involved in incidents where force was used.

In this policy essay, we offer three reflections that, we hope, will help policy makers interpret and act on the body of research in which Owens et al.'s (2017) study is situated. First, we discuss the importance of studying incidents where "nothing bad happened" (i.e., cases where officers did not resort to forceful means). Such everyday police-citizen encounters form the bulk of police work, but they are arguably the least studied. Second, we examine the challenges of training officers to automate the dialogue of procedural justice, not just in short burst encounters but also in more complex situations. Third, we emphasize the importance of considering the broader organizational culture when seeking to implement and assess the impact of training programs. Given the manner in which police work is structured, officers do not work in isolation but within varying workgroups (e.g., same squad, shift, and area). We explore, therefore, the organizational context in which "better cops" are supported to make, on a routine basis, quality decisions and treat citizens with dignity and respect.

\section{A Welcome Focus on Everyday Incidents and Noncoercion}

Wide-ranging incidents from low level to more serious (i.e., priority one calls, incidents that resulted in a documented crime report, or an arrest) were appropriately included in the current study by Owens et al. (2017). The goal of the experimental treatment was to strive to slow down the thinking of the officers to do everything possible to ensure all incidents (including volatile incidents) did not eventuate in an officer resorting to forceful means (beyond arrest) or engaging in behavior leading to some form of potential disciplinary outcome (e.g., a citizen complaint). First-line supervisors then asked officers in the treatment group to reflect and discuss how they used procedural justice during these incidents in which, to use the words of Owens et al., "nothing bad happened." Although the advantages of selecting such cases are well grounded, and carefully laid out by Owens et al., there is an additional benefit when viewed through the lens of the use-of-force literature. All too often researchers examine incidents where officers use force to resolve conflict rather than studying cases where officers refrained from using force. The result is that we know much about the correlates of force (Terrill and Mastrofski, 2002) but much less about its avoidance (Terrill, 2005).

As noted by Sykes and Brent (1983: 25) more than 30 years ago, "[o]ne comes to understand violence, not nonviolence, by studying violence." Thus, if we wish to know more about nonviolence, we need to study nonviolence. Similarly, if we are to know more about the avoidance of force in policing, it makes a lot of sense to study everyday incidents when force is not used. Sykes and Brent emphasized the talking aspect of police work and a 
strong reliance on officers' ability to persuade, suggest, and advise, finding that officers resort to force because they cannot exert control in other ways (i.e., via one's verbal ability), thereby leaving force as the only option. The use of such verbal communication clearly overlaps with many of the tenets of procedural justice. Owens et al. (2017) provide evidence demonstrating that officers who had received the specified procedural justice training (coupled with the direct supervisor meetings) were less likely to rely on coercive means in future incidents. As a result, they offer insight on how a particular training program can lead to a better cop (i.e., resolving conflict with less forceful means) or, alternatively, to good policing as opposed to bad policing (e.g., excessive force), on which police researchers have tended to focus over the years.

\section{Training Officers to Think, Speak, and Act With the Principles of Procedural Justice}

Training is an important foundation for promoting police efforts to use the principles of procedural justice in their everyday encounters, including those that are low level, benign incidents as well as those that are more volatile. By drawing on the Thinking, Fast and Slow ideas made famous by Nobel Laureate Daniel Kahneman (2011), coupled with insights from behavioral economics and psychology (particularly Augoustinos and Innes, 1990; Fiske and Taylor, 1991; Tversky and Kahneman, 1974; van Merrienboer and Ayers, 2005), Owens et al. (2017) sought to design a police training regime to automate the manner in which officers use procedural justice principles in their everyday encounters. In their trial, Owens et al. designed the intervention to capitalize on regular, conscious deployment of procedural justice policing, reinforcing the message through supervisory recognition of officers' use of procedural justice principles during low-risk, low-level incidents. The automation of routine, procedural justice policing was hypothesized to lead to efficiency gains because the officers no longer had to think through every step of every part of the procedurally just encounter.

For short burst encounters such as those characterized in the series of RCTs that tested the impact of procedural justice dialogue during routine traffic encounters (MacQueen and Bradford 2015; Mazerolle, Antrobus, Bennett, and Tyler, 2013; Mazerolle et al., 2012; Sahin et al., 2016), the capacity to train and then automate the principles of procedural justice should be straightforward. In the Queensland (Australia) Community Engagement Trial (QCET), for example, the requirement of all experimental officers to keep to the scripted dialogue was reinforced by a superior officer at the start of every shift. Patrol officers were given small cards to remind them of the dialogue, with the full written text on one side of the card and a checklist for the procedurally just dialogue on the flipside. A superior officer was rostered onto every shift to quality control both the control and experimental conditions, providing clear oversight of all 21,000 encounters that formed part of the trial (see Mazerolle et al., 2012). The careful quality control of the experimental dialogue, coupled with supervisory oversight, led to results that demonstrated how procedural justice 
dialogue could result in drivers being more satisfied with the encounters. Yet in Sahin and colleagues' (2016) trial in Turkey and MacQueen and Bradford's (2015) trial in Scotland, the scripting was a little different, the oversight not as rigorous, and the results revealed some backfire effects. These authors suggested that automating procedural justice dialogue creates some challenges, even for short burst encounters that might only last a minute or more.

The results of Owens et al. (2017), coupled with the earlier RCTs operationalizing procedural justice dialogue, also point to the overarching importance of supervisory oversight: When supervisors are watching, particularly in the formative stages of introducing a new, procedurally just dialogue, officers are more likely to get the hang of the tone and the language in ways that generate favorable outcomes. This was certainly the case for QCET (Mazerolle et al., 2012, 2013). Yet when execution of the dialogue lacks supervisory oversight, even simple, short encounters that are meant to convey the principles of procedural justice can lose their focus and thus their beneficial outcomes.

Longer, more complex encounters create many more training and oversight challenges than do the short burst encounters. It is no surprise, therefore, that the results of RCTs that have tested the outcomes of more complex, slow-thinking procedural justice training are encouraging, yet raise many unanswered questions. Rosenbaum and Lawrence (2017) examined the importance of procedural justice in the police recruit training environment. They found that procedural justice training does not change police recruits' attitudes toward procedural justice nor does it impact their self-reported interpersonal communication skills, but it does create more respectful and reassuring behaviors from police, as observed during role-playing scenarios. Skogan, Van Craen, and Hennessy's (2015) procedural justice training program in Chicago (U.S.) and Wheller and colleagues' (2013) training program in Manchester (U.K.) both found favorable outcomes, yet neither examined how supervisory input might have strengthened the results.

Thompson's (2016) RCT in Australia is unique in that a procedural justice knowledge and skills-based training program was implemented in which patrol officers were supported by supervisors in their efforts to build abilities to apply, in a practical way, the principles of procedural justice in the everyday operational environment. In Thompson's trial, real-time supervisory observations were made for each and every patrol officer encounter (for both control and experimental officers), revealing that the training had a significant positive effect in the weeks immediately after the training. By 8 weeks after the training, however, the effect had decayed (Thompson, 2016). These results demonstrate the substantial challenges to automating procedural justice policing: In complex encounters, the task of creating procedurally just dialogue is difficult, and even with supervisory oversight, it is hard to sustain the capacity to deliver procedural justice dialogue over time. Automating and making the slow thinking of procedural justice stick is, we can see, difficult to do. 


\section{Embedding Procedural Justice Policing Within Police Culture}

Although Owens et al. (2017) assessed the impact of procedural justice meetings between direct supervisors and individual officers on subsequent reported police behaviors, future replications or expansions of such training should also be aimed at considering the broader police culture, especially potential workgroup effects. Police culture involves a set of orientations transmitted and shared among officers to cope with the common strains of their occupational (i.e., street-level interactions with citizens) and organizational (i.e., departmental interactions with supervisors) work environments (Paoline and Terrill, 2014). The specific attitudes, values, and norms; the various levels of aggregation (i.e., occupation, organization, subgroup); and the degree of sharedness have all been part of the various cultural accounts of police. Paoline (2003: 200) argued that police culture is useful for understanding "many facets of policing from learning the ropes, day-to-day functioning, investigating forms of police deviance, keeping police accountable, and the success of reform efforts."

As noted by Ingram, Paoline, and Terrill (2013), officers working in the same workgroup (i.e., assigned to the same squad, on the same shift, and in the same precinct) are exposed to similar environmental characteristics, are interdependent (see also Klinger, 1997), and interact with each other on a regular basis. As a result, officers in the same group develop shared cultural prescriptions regarding how to cope with the uncertainties of their work environments. Because workgroups also represent the formal, structural boundaries of police organizations, meaningful cultural variation can also exist across workgroups. This framework was empirically tested, and the findings helped researchers to establish construct validity for aggregating officers' cultural prescriptions (i.e., attitudes) and to treat them as a shared, workgroup culture. Hence, police culture represents a collective property where individual officer attitudes determine the substantive content of group culture, but the culture is not solely derived from any single officer in the group.

Within the context of Owens et al.'s (2017) study, the authors treated officers as if they operated within a vacuum, failing to account for broader organizational influences such as workgroups (or precincts). The manner in which individual officers were randomly assigned to treatment and control groups does allow, however, one to determine the influence of workgroups on the range of outcomes reported. Yet without fully addressing the need for broader organizational consideration or subsequent reform, it is not clear why direct supervisors having a meeting with individual officers to "slow down" their thinking might be a good way to build a "better cop." The qualitative interviews with the officers about their meetings with supervisors are instructive in that officers were "generally indifferent to the meetings," would have preferred to talk more about "exciting" events rather than trivial ones, and interacting with their sergeants "was considered a departure from standard practice." How such perceptions may cluster, or not, within the broader organizational climate is not readily answered. Perhaps such findings are indicative of an organizational culture throughout the Seattle Police Department that embraces the principles of procedural 
justice. Alternatively, it is likely that some workgroups may more strongly align with the precepts of procedural justice training while others may be more reluctant. From a policy standpoint, knowing how best to bolster, reinforce, and target training mechanisms will offer the greatest chance for successful and sustained changes for police to make routine, automated quality decisions and quality treatment of citizens in the communities they serve.

\section{Conclusion}

Building a "better cop" is an eternal challenge for police training academies, supervisors, and the myriad personnel that are vested in translating the Peelian principle of "policing by consent" into practice. For more than 200 years, police in Western democracies have strived to exercise their powers with the implicit consent of their fellow citizens, creating legitimacy through transparency, integrity, and accountability. In this policy essay, we have applauded Owens et al. (2017) not just on their focus on volatile incidents where force may be used but also on their efforts to automate the dialogue of procedural justice policing in everyday incidents that may involve no more than a conversation between a police officer and a citizen. Owens et al. argue that it is these simple encounters attracting no special attention that serve as a training ground for fostering automatic procedurally just dialogue. By supervisors providing oversight and commentary on these encounters that do not go bad, the authors show that these experimental officers were less likely to resolve incidents with an arrest or to be involved in incidents where force was used.

In our policy essay, we have explored how difficult it is to slow down the thinking of police to embrace the principles of procedural justice in their everyday dialogue. We have agreed with Owens et al. (2017) in making the role of supervisory oversight central to building a "better cop" and thereby achieving better outcomes. We raise the issue, however, as to the importance of sustaining the gains made through interventions that strive to mainstream procedurally just approaches in policing. The results of the RCT by Thompson (2016) are sobering: The effects of the training and supervisory oversight wore off after 8 weeks. It may be that the inculcation of procedurally just policing cannot be fully realized without paying attention to building a culture that embraces the principles of procedural justice, not just for the entire organization, but also for individual workgroups and individual officers.

\section{References}

Augoustinos, Martha and John M. Innes. 1990. Towards an integration of social representations and social schema theory. British Journal of Social Psychology, 29: 213-231.

Bates, Lyndel, Emma Antrobus, Sarah Bennett, and Peter Martin. 2015. Comparing police and public perceptions of a routine traffic encounter. Police Quarterly, 18: 442-468.

Bottoms, Anthony and Justice Tankebe. 2012. Beyond procedural justice: A dialogic approach to legitimacy in criminal justice. The Journal of Criminal Law and Criminology, 102: 119-170. 
Fiske, Susan T. and Shelley E. Taylor. 1991. Social Cognition. New York: McGraw-Hill.

Ingram, Jason, Eugene A. Paoline III, and William Terrill. 2013. A multilevel framework for understanding police culture: The role of the workgroup. Criminology, 51: 365397.

Kahneman, Daniel. 2011. Thinking, Fast and Slow. New York: Farrar, Straus \& Giroux.

Klinger, David A. 1997. Negotiating order in patrol work: An ecological theory of police response to deviance. Criminology, 35: 277-306.

Lowrey, Belen, Edward Maguire, and Richard R. Bennett. 2016. Testing the effects of procedural justice and over accommodation in traffic stops: A randomized experiment. Criminal Justice and Behavior, 43: 1430-1449.

MacQueen, Sarah, and Ben Bradford. 2015. Enhancing public trust and police legitimacy during road traffic encounters: Results from a randomised controlled trial in Scotland. Journal of Experimental Criminology, 11: 419-443.

Mazerolle, Lorraine, Emma Antrobus, Sarah Bennett, and Tom R. Tyler. 2013. Shaping citizen perceptions of police legitimacy: A randomized field trial of procedural justice. Criminology, 51: 33-64.

Mazerolle, Lorraine, Sarah Bennett, Emma Antrobus, and Elizabeth Eggins. 2012. Procedural justice, routine activities and citizen perceptions of police: Main findings from the Queensland Community Engagement Trial. Journal of Experimental Criminology, 8: 343-367.

Owens, Emily, David Weisburd, Karen L. Amendola, and Geoffrey P. Alpert. 2017. Can you build a better cop? Experimental evidence on supervision, training, and policing in the community. Criminology \& Public Policy. This issue.

Paoline, Eugene A. III. 2003. Taking stock: Toward a richer understanding of police culture. Journal of Criminal Justice, 31: 199-214.

Paoline, Eugene A. III and William Terrill. 2014. Police Culture: Adapting to the Strains of the Job. Durham, NC: Carolina Academic Press.

President's Task Force on 21st Century Policing. 2015. Final Report of the President's Task Force on 21st Century Policing. Washington, DC: Office of Community Oriented Policing Services. Retrieved from cops.usdoj.gov/pdf/taskforce/TaskForce_FinalReport.pdf.

Rosenbaum, Dennis P. and Daniel S. Lawrence. 2017. Teaching procedural justice and communication skills during police-community encounters: Results of a randomized control trial with police recruits. Journal of Experimental Criminology. Epub ahead of print. https://doi.org/10.1007/s11292-017-9293-3.

Sahin, Nusret, Anthony A. Braga, Robert J. Apel, and Rod K. Brunson. 2016. The impact of procedurally just policing on citizen perceptions of police during traffic stops: The Adana Randomized Controlled Trial. Journal of Quantitative Criminology. Epub ahead of print. https://doi.org/10.1007/s10940-016-9308-7.

Skogan, Wesley G., Maarten Van Craen, and Cari Hennessy. 2015. Training police for procedural justice. Journal of Experimental Criminology, 11: 319-334.

Sykes, Richard E. and Edward E. Brent. 1983. Policing: A Social Behaviorist Perspective. New Brunswick, NJ: Rutgers University Press. 
Terrill, William. 2005. Police use of force: A transactional approach. Justice Quarterly, 22: $107-138$.

Terrill, William and Stephen D. Mastrofski. 2002. Situational and officer-based determinants of police coercion. Justice Quarterly, 19: 215-249.

Thompson, Ian. 2016. The impact of procedural justice training on first year constables' interactions with citizens: A randomized controlled trial (master's thesis, University of Cambridge, U.K.). Retrieved from www.crim.cam.ac.uk/alumni/ theses/Ian\%20Thompson.pdf.

Tversky, Amos and Daniel Kahneman.1974. Judgment under uncertainty: Heuristics and biases. Science, 185: 1124-1131.

Tyler, Tom R. 2006 [1990]. Why People Obey the Law. Princeton, NJ: Princeton University Press.

Tyler, Tom R., Jeffrey Fagan, and Amanda Geller. 2014. Street stops and police legitimacy. Journal of Empirical Legal Studies, 11: 751-785.

van Merrienboer, Jeroen J. G. and Paul Ayers. 2005. Research on cognitive load theory and its design implications for e-learning. Educational Technology Research and Development, 53: 5-13.

Wheller, Levin, Paul Quinton, Alistair Fildes, and Andy Mills. 2013. The Greater Manchester Police Procedural Justice Training Experiment-The Impact of Communication Skills Training on Officers and Victims of Crime. London, U.K.: College of Policing.

Lorraine Mazerolle is a former Australian Research Council (ARC) laureate fellow, a professor in the School of Social Science at The University of Queensland, and a chief investigator with the ARC Centre of Excellence for Children and Families over the Life Course (LCC). She is editor-in-chief of the Journal of Experimental Criminology and a fellow of the American Society of Criminology (ASC), the Academy of Experimental Criminology (AEC), and the Academy of the Social Sciences Australia. Lorraine is the past chair of the ASC's Division of Experimental Criminology and the recipient of the 2016 ASC Division of Policing Distinguished Scholar Award, the 2013 AEC Joan McCord Award, and the 2010 ASC Division of International Criminology Freda Adler Distinguished Scholar Award. Her research interests include experimental criminology, policing, drug law enforcement, regulatory crime control, and crime prevention.

William Terrill is a professor in the School of Criminology at Arizona State University. His research is focused on police behavior, with an emphasis on police use of force and police culture. Prof. Terrill's work has appeared in a variety of scholarly journals, as well as two books titled Police Coercion: Application of the Force Continuum (2001, LFB Scholarly Publishing) and Police Culture: Adapting to the Strains of the Job (2014, Carolina Academic Press). 